RELATIONSHIPS BETWEEN

AEROBIC AND ANAEROBIC

CARDIOPULMONARY INDICES

OF YOUNG MALE SOCCER PLAYERS

WHEN PERFORMING LABORATORY

FUNCTIONAL TESTS

\title{
Borislava Petrova
}

National Sports Academy "Vassil Levski", Sofia, Bulgaria

\begin{abstract}
Soccer is a high-intensity intermittent team sport where both the aerobic and anaerobic energy systems contribute to the physiological demands of the game. The study aims to search and determine relationships between the values of cardiopulmonary and gas exchange indices during frequently used laboratory tests - the CardioPulmonary Exercise Test (CPET) and the Wingate Anaerobic Test (WAnT), exploring the capacity of the energy systems. Forty-seven soccer players (15.06 \pm 0.84 years of age) performed both tests as Oxygen uptake $(\mathrm{VO})$, Oxygen pulse $\left(\mathrm{O}_{2} \mathrm{HR}\right)$, Pulmonary ventilation (VE), Volume of expired air (VTex), and Breath frequency (BF) were measured online using a breathby-breath cardiopulmonary exercise testing system. Ergometric achievements during WAnT: PP (Peak Power) 662.4 土121.2 W; AP (Average Power) 494.67 $\pm 98.5 \mathrm{~W} ; \mathrm{FI}$ (Fatigue Index) $61.2 \pm 28.7 \%$. There was no correlation between WAnT PP and AP and maximum power output in CPET. WAnT VE and VTex correlate significantly with CPET VO $\max (r=.676$ and $r=.772$, respectively). The main finding was a presence of approximately identical maximal values of cardiopulmonary parameters achieved in the very different in duration and intensity CPET and WAnT: insignificant differences between CPET versus WAnT: $V_{2} \max \left(55.97 \pm 2.02\right.$ versus $\left.56.02 \pm 17.3 \mathrm{ml} . \mathrm{kg} \mathrm{min}^{-1}\right) ; \operatorname{VEmax}(133.96 \pm 21.77$ versus $126.77 \pm 24.77$ l. min $\left.^{-1}\right)$; VTex $\max (2.19 \pm 0.37$ l versus $2.06 \pm 0.43 l)$; BFmax (62.20 versus 75.43. $\mathrm{min}^{-1}$ ). We assume that when conducting WAnT with simultaneous registration of respiration, together with the indices of athletes' power output, reliable information about the magnitude of VO2max and other cardiopulmonary parameters of players could be obtained. This will greatly facilitate the ongoing control of the exercise conditioning status of athletes.
\end{abstract}

Keywords: Cardiopulmonary exercise test, Wingate anaerobic test, Aerobic capacity, Anaerobic power

\section{INTRODUCTION}

Soccer is the most popular game in the world, which men and women of all ages practice both in the form of highly emotional entertainment and as a highly qualified sport. The modern methodology of sports training begins at an early age when the mastery of sports techniques is particularly successful. At the same time, however, training effects are carried out to increase the functional capabilities of the body of the athletes. The training programs focus on the specific features of the given sport, especially on the nature of the motor abilities, structure, and intensity. The latter determines the participation and activity of energy delivering systems needed for the physical effort.

McMillan (2005) classified soccer as a high-intensity intermittent team sport with an acyclic structure. During competitive soccer match play, elite players cover a distance of 
about $10-12 \mathrm{~km}$ at an average intensity close to the anaerobic threshold, being $80-90 \%$ of maximal heart rate (HR max) or $70-80 \%$ of maximal oxygen uptake ( $\left.\mathrm{VO}_{2} \max \right) . \mathrm{VO}_{2} \max$ is considered to be the most important component of endurance performance. It has been found that aerobic metabolism provides $90 \%$ of the energy cost of soccer match play (Bangsbo,1994). Therefore, high aerobic capacity is crucial for successful performance during a football match. Aerobic endurance is one of the main fitness components important for success in soccer (Helgerud J et al., 2001) which observed a significant correlation between maximal oxygen uptake and distance covered during a soccer match (Hoff, 2005).

Soccer is characterized by frequent changes of intensity, short breaks recovery, sudden stops, and changes of direction, i.e., athletes make efforts of intermittent nature in training and competition. During a soccer match, young soccer players perform approximately $10-15$ seconds of sprints $(5,10$, and $20 \mathrm{~m})$ every 90 seconds of the game (Stølen et al., 2005). The energy requirement is met by involving the anaerobic metabolism (Da Silva et al., 2010). It is noteworthy to mention that anaerobic fitness during growth and development has not received the same attention from researchers as aerobic fitness is.

Bangsbo et al. (2005) underline that both the aerobic and anaerobic energy systems contribute to the physiological demands of the soccer game. The anaerobic system is considered to be of great importance to perform ballistic movements such as sprinting, jumping, and changing direction rapidly (Stølenet al., 2005). These actions repeated over time (speed-strength endurance) at high intensity determine the high lactate concentrations. In this perspective, the aerobic system is crucial in increasing the lactate removal rate during the phases performed at lower intensities (Di Giminiani, Visca, 2017, Glaister, 2005, Spen- cer et al., 2005).

Detailed information about one's maximal aerobic capacity $\left(\mathrm{VO}_{2} \max \right)$ and anaerobic power can be obtained by valid and reliable laboratory methods. The $\mathrm{VO}_{2}$ max of the athletes is determined by progressive intensity and continuous effort treadmill protocols or pedaling on a stationary bicycle, validating the respiratory anaerobic threshold and the respiratory exchange ratio (RER) as well. Most popular are the Cardiopulmonary Exercise Tests (CPET).

The athlete's anaerobic power and capacity are defined by the Wingate anaerobic test (WAnT), a 30-s all-out test where the work done is used to measure the anaerobic capacity. It provides information about both the alactic and lactic anaerobic energy transfer systems.

It should be born in mind that not only the development of a high level of physical work capacity is the single indicator of a successful player but represent the fundamental prerequisite of game performance (Chamari et al., 2004).

The scientific literature abounds in data on the level of aerobic and anaerobic capacity of elite athletes in various sports, the applied training methods, but research in adolescents is significantly limited (Armstrong, Welsman, Chia, 2001, Vanderford, 2004, Armstrong, Welsman, Chia, 2001, Vanderford, 2004).

The present study aimed to search and determine the relationships between cardiopulmonary and gas exchange indices during frequently used laboratory tests: CPET and WAnT. We hypothesized the existence of interconnections between the anaerobic and the aerobic physiological parameters recorded during the maximal cardiopulmonary exercise test (CPET) and the Wingate anaerobic test (WAnT). Establishing the presence of interrelationships will allow a more in-depth interpretation of the experimental results. 


\section{METHODOLOGY}

\section{Participants}

Forty-seven adolescent soccer male players were studied $(15.06 \pm 0.84$ years of age; height $172.91 \pm 7.76 \mathrm{~cm}$; body weight 60.11 $\pm 8.63 \mathrm{~kg}$; BMI $20.13 \pm 1.77$ ) who were familiar with exhaustive exercises, volunteered to participate in this study. The subjects were fully informed of the details and discomfort associated with the experiments before they and their parents gave their informed consent to volunteer. Medical professionals seek information on any disease they might have before, their present health status, and any medication they could have taken. The following constituted the exclusion criteria: current infection, history of chronic disease, use of antibiotics, herbal, antioxidant, and steroid-containing supplements. The study protocols were conducted by the Helsinki Declaration for Ethical Treatment of Human Subjects and were evaluated and approved by the Ethics Committee of National Sports Academy, Sofia, Bulgaria.

\section{Limitations}

Blood lactate samples were not taken after the cessation of the exercise. Boys are characterized by lower lactate peak levels and shorter time lag before reaching it. Children generally observed faster performance recovery following short, high-intensity exercise. It is considered that children are better equipped for physical exercise supported by oxidative metabolism.

\section{Exercise testing procedures}

All study procedures were done in the High-Performance Physiology Laboratory at the Center for Scientific and Applied Research in Sport, National Sports Academy "Vassil Levski" Sofia. At the time of the study, the soccer players were in their competition phase of the annual training cycle 2017-2018. The training plan included evenly distributed work for aerobic and anaerobic endurance. The players train systematically for 5 years, five times a week, once a day.

Participants were tested twice in two separate sessions with an interval of 48 hours between sessions. During the first visit to the physiology laboratory, anthropometric measurements were made on the soccer players, after which they performed a cardiopulmonary exercise test (CPET) to measure maximal aerobic power $\left(\mathrm{VO}_{2} \max \right)$. In the second session, the 30-second WAnT was carried out.

Bioelectric Impedance (In Body 230) was used to measure body weight (to the nearest 0.1 $\mathrm{kg}$ ) and body composition and portable stadiometer (SECA, $225 \mathrm{UK}$ ) for stature (to $0.1 \mathrm{~cm}$ ).

A maximal CPET was used to measure $\mathrm{VO}_{2}$ max: initial treadmill speed $6 \mathrm{~km} \cdot \mathrm{h}^{-1}$, step length 90 seconds, speed increase $1.2 \mathrm{~km} . \mathrm{h}^{-1}$, constant incline $2.5^{\circ}$ (Iliev, 1970). The test was stopped when a participant could not continue running at the actual velocity and slope. Strong verbal encouragement was provided to each participant as they came to the end of the CPET. Oxygen uptake $\left(\mathrm{VO}_{2}\right)$, carbon dioxide output $\left(\mathrm{VCO}_{2}\right)$, oxygen heart rate $\left(\mathrm{O}_{2} \mathrm{HR}\right)$, pulmonary ventilation (VE), the volume of exhaled air (VTex), and breath frequency (BF) were measured online using a breath-by-breath cardiopulmonary exercise testing system (Oxycon Pro, Jaeger-Pro, Germany). Before each test, the gas analyzer was calibrated with known certified gas concentration.

During CPET, heart rate (HR) and oxygen pulse $\left(\mathrm{O}_{2} \mathrm{HR}\right)$ were monitored continuously using a wireless HR monitor (Polar RS800 SD, Finland) and were synchronized in time with the ventilatory signals.

\section{0-Wingate anaerobic test}

The 30s WAnT was performed on a mechanically braked cycle ergometer (Monark, 
894 E, Stockholm, Sweden) as described by Inbar et al. (Inbar, 1996).

The following variables were determined: peak power output (PP), average power output (AP), and anaerobic fatigue index (FI). PP was the highest power generated during the test; AP was calculated as the average power during the entire 30-s period of the test. The FI was calculated as the percentage of power output drop from the maximal power output throughout the trial.

In addition, the subjects were connected to a portable gas analyzer Meta Max 3B, Cortex, Leipzig to allow the respiratory parameters to be recorded simultaneously with the power output realized during the test.

The test started with a standardized warming up of 5 min cycling at $60 \mathrm{~W}$ and $60 \mathrm{rev} /$ min, including two sprints, each lasting $3 \mathrm{sec}$, performed at the end of the $3 \mathrm{rd}$ and the 5 th min. The seat height and handle were individually adjusted for the subject's comfort, with the legs being nearly fully extended during each pedal revolution. After $5 \mathrm{~min}$ rest, the subjects were instructed to pedal as fast as possible throughout the 30 -sec test. A resistance corresponding to $7.5 \%$ of the body mass was applied after an acceleration phase lasting $5 \mathrm{~s}$. Verbal feedback for the time remaining was provided at 15,10 , and $5 \mathrm{sec}$ and verbal encouragement was given through the test. The subjects continued pedaling after completing the test with no load for several minutes to cool down.

\section{Statistical analysis}

The SPSS 19 (IBM, USA) was used for all statistical analyses. Data are presented as mean $\pm \mathrm{SD}$. The assumption of normality was tested with the Kolmogorov-Smirnov test on each variable. The level of statistical significance was set at $p<.05$. A Pearson product-moment correlation was used to determine the relationship between variables among the two tests. Magnitude of correlation was qualitatively ranked according to as follows: $r \leq .1$, negligible; $.1<r \leq .3$, week; $.3<r \leq .5$, moderate; $.5<r \leq .7$, strong; $.7<$ $r \leq .9$, very strong; and $r>.9$, almost perfect.

\section{RESULTS}

The recorded anthropometric data of the investigated subjects are placed in Table 1.

Table 1. Anthropometric characteristics of the soccer players $(n=47)$

\begin{tabular}{lcc}
\hline Parameter & Mean & SD \\
\hline Age (years) & 15.06 & .84 \\
Height (cm) & 72.91 & 7.76 \\
Weight (kg) & 60.11 & 8.63 \\
BMI (kg.m-2) & 20.13 & 1.97 \\
FFM (kg) & 55.4 & 7.87 \\
\hline
\end{tabular}

BMI - Body Mass Index; FFM - Free Fatty Mass

Eighteen of the studied group participants were 14 years old, fourteen were fifteen years old, and 15 were 16 years old. In all three cases, the distribution was normal, and the differences in the values of the studied parameters were most often statistically insignificant. This gave us reason to interpret the experimental results obtained simultaneously for the whole group of 47 players.

Table 2 represents the power achieved during the WAnT. 
Table 2. Ergometric indices achieved during the performance of WAnT $(n=47)$

\begin{tabular}{lcc}
\hline Parameter & Mean & SD \\
\hline PP(W) & 662.38 & 112.22 \\
PP $\left(\mathbf{W} . \mathbf{k g}^{-1}\right)$ & 11.25 & 2.63 \\
AP $(\mathbf{W})$ & 494.68 & 98.55 \\
AP $\left(\mathbf{W . k g} \mathbf{k g}^{-1}\right)$ & 8.22 & .99 \\
FI\% & 61.2 & 28.72 \\
\hline
\end{tabular}

PP-Peak Power; AP-Average Power; FI\% - Fatigue Index

As already noted, when performing the the test. Furthermore, it provides power output WAnT, the subjects were connected to a portable gas analyzer to allow the respiratory parameters to be recorded simultaneously (breath by breath) with the power output realized during Table 3.

Table 3. Cardiopulmonary data during the performance of WAnT $(n=47)$

\begin{tabular}{|c|c|c|c|c|c|}
\hline Indices & Average & SD & Indices & Average & SD \\
\hline Time (s) & 30 & 30 & $\mathrm{O}_{2} \mathrm{HRmax}(\mathrm{ml})$ & 16.28 & 4.31 \\
\hline Wmax & 662.38 & 112,2 & VEmax (L.min $\left.{ }^{-1}\right)$ & 126.77 & 24.27 \\
\hline $\mathrm{VO}_{2} \max \left(\mathrm{ml} \cdot \mathrm{min}^{-1}\right)$ & 3363.77 & 859.4 & VTexmax (L) & 2.061 & 0.43 \\
\hline $\mathrm{VO}_{2} \max \left(\mathrm{ml} \cdot \mathrm{kg}^{-1}\right)$ & 56.02 & 17.3 & BFmax.min ${ }^{-1}$ & 75.43 & 13.45 \\
\hline HR (B.min $\left.{ }^{-1}\right)$ & 184.26 & 8.95 & RER & 1.18 & .09 \\
\hline
\end{tabular}

$V_{2}$ max-Maximal Oxygen Consumption; HR - Heart Rate; $\mathrm{O}_{2} H R$ - Oxygen Heart Rate; VE - Pulmonary Ventilation; VTex-Tidal Volume Expired; BF - Breath Frequency; RER - Respiratory Exchange Ratio

Based on these data, there were calculated tion of the Wingate test (Table 4). The calculaergometric and respiratory indices reflecting tion of these data was performed according to the relative share of participation of anaerobic the method proposed by Stefanova and Petrova and aerobic energy systems in the implementa- (2017) for analysis of the Wingate test results.

Table 4. Calculated ergometric and respiratory indices achieved in the WAnT $(n=47)$

\begin{tabular}{lccccc}
\hline Indices & Average & SD & Indices & Average & SD \\
\hline W 30 s & 14263.1 & 2568 & O $_{2}$ excess $(\mathbf{m l})$ & 212.9 & 102.6 \\
VO $_{2}$ 30 s (ml) & 1067.9 & 175.8 & W anaerobically & 4566.5 & 1858 \\
$\mathbf{O}_{2}$ deficit (ml) & 224.2 & 90.2 & W anaerobically \% to W 30s & 31.9 & 10.8 \\
\hline
\end{tabular}

W30 s-Total Power Output 30 s; VO 30 s-Total O Uptake 30 s'; W Anaerobic - Watts Performed Anaerobically

The maximum values of the cardiopulmo- mance of CPET on the treadmill are presented nary parameters achieved during the perfor- in Table 5. 
Table 5. Cardiorespiratory maximal responses data during performance CPET $(n=47)$

\begin{tabular}{|c|c|c|c|c|c|}
\hline Indices & Average & SD & Indices & Average & SD \\
\hline Time (s) & 737.59 & 73.46 & $\mathrm{O}_{2} \mathrm{HRmax}(\mathrm{ml})$ & 17.05 & 2.88 \\
\hline Wmax & 231.22 & 40.64 & VEmaxL.min ${ }^{-1}$ ) & 133.96 & 21.77 \\
\hline $\mathrm{VO}_{2} \max \left(\mathrm{ml} \cdot \mathrm{min}^{-1}\right)$ & 3448.2 & 513.43 & VTex max (L) & 2.19 & .37 \\
\hline $\mathrm{VO}_{2} \max \left(\mathrm{ml} . \mathrm{kg} \cdot \mathrm{min}^{-1}\right)$ & 55.97 & 2.02 & BFmax.min ${ }^{-1}$ & 62.20 & 7.99 \\
\hline HRmax B.min ${ }^{-1}$ & 203.72 & 8.16 & RER & 1.15 & .06 \\
\hline
\end{tabular}

Table 6 presents the correlations between during the performance of CPET and WAnT. the ventilator and cardiopulmonary parameters

Table 6. Correlations between ventilatory and cardiopulmonary parameters achieved during performance WAnT and CPET $(n=47)$

\begin{tabular}{|c|c|c|c|c|c|}
\hline WAnT & CPET & $\mathbf{r}$ & WAnT & CPET & $\mathbf{r}$ \\
\hline \multirow{4}{*}{$\begin{array}{l}\text { VEmax } \\
\left(\text { l.min }^{-1}\right)\end{array}$} & VEmax $\left(1 . \mathrm{min}^{-1}\right)$ & .665 & \multirow{4}{*}{ VTex (l) } & VEmax $\left(1 . \mathrm{min}^{-1}\right)$ & .623 \\
\hline & $\mathrm{VO}_{2} \max \left(\mathrm{ml} \cdot \mathrm{kg} \cdot \mathrm{min}^{-1}\right)$ & .676 & & BTex (1) & .809 \\
\hline & $\mathrm{O}_{2} \mathrm{HRmax}(\mathrm{ml})$ & .665 & & $\mathrm{O}_{2} \mathrm{HRmax}(\mathrm{ml})$ & .664 \\
\hline & VTex (1) & .536 & & $\mathrm{VO}_{2} \max \left(\mathrm{ml} \cdot \mathrm{kg} \cdot \mathrm{min}^{-1}\right)$ & .772 \\
\hline
\end{tabular}

Correlations are significant at the .001 level (2-tailed)

\section{DISCUSSION}

At the time of the study, the soccer players were in their competition phase of the annual training cycle 2017-2018. The training plan included evenly distributed work for aerobic and anaerobic endurance. They train systematically for 5 years, five times a week, once a day.

The present study aimed to investigate some relationships between the values of aerobic and anaerobic indices when performing the most commonly used laboratory tests for their determination: the CPET and the WAnT. Therefore, we focus first on the main indicators based on which the quality of the test performance is determined.

The measurement of $\mathrm{VO}_{2}$ max is commonly used to monitor athletes' training status and can help determine the training regime. Enhanced aerobic endurance in soccer players improved soccer performance by increasing the distance covered, enhancing work intensity, and increasing the number of sprints and involvements with the ball during a match (Helgerud et al., 2001). The analysis of the respiratory gas exchange with cardiopulmonary exercise tests provides the opportunity to assess the cardiovascular and pulmonary responses to metabolic stress created during exercise (Edwards et al., 2003, McMillan et al., 2005).

The data presented in Table 5 shows that the soccer players covered two of the criteria for reaching the maximal oxygen consumption: the actual HRmax was $100.04 \%$ from the expected, and the Respiratory Exchange Ratio (RER) was 1.15.

At the end of lasting an average of 12-minutes of CPET (Table 5), the young players reach a maximal aerobic capacity close to that of qualified players. The average $\mathrm{VO}_{2} \mathrm{~m}$ ax for international level male soccer players has been reported to range between 55 and 68 ml.kg.min ${ }^{-1}$ (Hoff, 2005). Ciprian and Vojtech 
(2011) established $62.9 \pm 5.12 \mathrm{ml} . \mathrm{kg} \cdot \mathrm{min}^{-1} \mathrm{VO}-$ ${ }_{2}$ max in 17 years old soccer players; Tønnessen et al. (2012) reported $\mathrm{VO}_{2} \max$ values $\sim 62-64$ ml.kg. $\min ^{-1}$ for adolescent soccer players.

The average measured HRmax of the investigated soccer players corresponds to the Fox prediction equation (HRmax $=220$-age). The data published by Gharbi et al. (2015) $197 \pm 8.7$ and Nikolaidis $(2015)-200 \pm 7.9$ beats per min are similar to those of the adolescent soccer players.

The values of the ventilatory parameters do not differ from those established by other researchers in the CPET.

$\mathrm{VO}_{2}$ max of performers of the CPET in this study $(55.97 \pm 2.02$ ml.kg.min-1) differ slightly from those experienced with adult athletes. The values for $\mathrm{VO}_{2}$ max in the current study were significantly higher than values reported for the general population of the same age (Vanden and Eynde, 1988). This aerobic capacity is reached at a maximum power output equal to $231.22 \pm 40.64$ watts. It was reported $\mathrm{VO}_{2} \max$ was $62.9 \pm 5.12 \mathrm{ml} . \mathrm{kg}^{-1}$ for 17 years old soccer players (Ciprian and Voitech, 2011) and $62-64 \mathrm{ml} . \mathrm{kg}^{-1}$ for adolescent soccer players (Tonnessen et al., 2012).

The anaerobic profile of the participants in this study (Table 2) was superior to the general population. Peak and Average Power achieved from adolescent soccer players are close to data published by other authors (Armstrong, 2001, Stole et al., 2005, Üçok,2005, Cipryan, Gajda, 2011, Gharbi et al., 2015). Since the test aims to determine the anaerobic ability of the person, it is of particular importance to determine the relationship between oxygen deficit (as a marker for anaerobic power) and the excess amount of oxygen needed during the test performance to pay off the deficit (Table 4). Data of the Watts values obtained when performing the anaerobic component and the percentage contribution to the Total power out- put (W30 s) can also be added to the Wingate ergometric data. The applied methodology of simultaneous registration of ergometric and cardiorespiratory indicators makes it possible to determine the oxygen needs for physical exertion at any time of the load and hence the amount of accumulated oxygen deficit and the excess of oxygen consumed for its payment. It can be seen that in our case, the oxygen deficit and excess are very close. Only $31.9 \%$ of the achieved Watts are anaerobically provided. According to Cavanagh and Jacobs (1988), however, net $\mathrm{VO}_{2}$ during the WAnT could account for about $18.5 \%$ of the work performed; Serresse et al. (2007) report a $28 \%$ share of oxidative processes during the 30 -second supramaximal test. They concluded that the $30 \mathrm{~s}$ is not strictly anaerobic, although it has a large anaerobic component.

The maximal power output is three times larger than that of CPET. Since the distribution of power data per $\mathrm{kg}$ body weight was not normal, comparisons with absolute values were made. We did not find a relationship between the size of the ergometric achievements of the subjects when performing a WAnT and the CPET. There is no correlation between the maximum power reached in the CPET test and the peak, and average power is shown when performing WAnT (correlation coefficient $r=$ .141 and .024 , respectively).

In connection with the purpose of our study during the implementation of the WAnT, we registered the cardiorespiratory indicators as those when conducting CPET. Unexpectedly for us, the data obtained in both tests are practically identical (Tables 3 and 5). The differences between the data for most investigated parameters are statistically insignificant. The only exceptions are the heart and the breath frequency and the oxygen heart rate, where the differences in favor of CPET are very small but statistically significant. 
Heart rate at the end of CPET exceeds that predicted for individuals of this age and correlates largely with HRmax achieved during WAnT $(r=.676)$. As an indicator of the systolic volume of the heart, the oxygen pulse is at a normal rate. The correlation between the $\mathrm{O}_{2} \mathrm{HR}$ in the two maximal tests was $r=.650$.

The strongest connections between the WAnT and the CPET were found in the ventilator parameters (Table 6). Pulmonary ventilation and respiratory depth during WAnT correlate largely with the most important indicators for aerobic metabolism - $\mathrm{VO}_{2}$ max. Obviously, in the oxygen supply of the muscles at supramaximal load such as the Wingate test, the largest share has the pulmonary ventilation and especially the depth of breathing. To the best of our knowledge, studies comparing the cardiorespiratory response to the $\mathrm{VO}_{2}$ max test and Wingate test have not been carried out.

The identical maximum values of cardiopulmonary parameters achieved in the very different in duration and intensity WAnT and CPET raise the important question of the physiological mechanisms that contribute to this phenomenon.

The control of breathing during exercise is the combined and simultaneous effect of several chemical and neural stimuli. The neurogenic stimuli from the cerebral cortex combined with feedback from the active limbs cause the abrupt increase in ventilation as exercise begins (Mc Ardle et al., 1996).

Analysis of the oxygen transport chain elements from the lungs to the enzymes in the muscle cells when performing the CPET showed a central limitation - the heart's maximal cardiac output. In activities that involve dynamic work with large muscle mass, as in running, it is generally assumed that $\mathrm{VO}_{2} \max$ is primarily limited by maximal cardiac output (Mc Ardle et al., 1996). The heart's stroke volume has been thought to be the most important factor, especially since it can be twice as high in trained athletes compared to sedentary individuals (Ferretti, 2014).

Data on high oxygen consumption when performing WAnT by trained cyclists are found by Hawley et al. (1992). They found highly significant relationships between Peak Power (W), $\mathrm{VO}_{2} \max (r=.97 ; P<.0001)$, and 20 $\mathrm{km}$ cycle time. They concluded that for trained cyclists, the $\mathrm{VO}_{2}$ max could be accurately predicted from WPeak.

The Wingate test is used as a measure of the anaerobic capacity. However, a significant number of studies show that aerobic metabolism is involved to a large extent in its implementation. Smith and Hill (1991) concluded that glycolytic power peaks within the first $15 \mathrm{~s}$ of high-power exercise and also, aerobic metabolism responds quickly during ,anaerobic” exercise and makes a significant contribution to the work performed. Our measurements showed a significant aerobic energy release even during $30 \mathrm{~s}$ exercise ( $31.9 \%$ ). This is in accordance with Medbo and Tabata (1989), determining the accumulated oxygen deficit. The Wingate test does not exhaust the anaerobic capacity and may not be a proper anaerobic capacity test. Wingate test can be as high as $28 \%$ of the aerobic contribution for sprinters and $45 \%$ for endurance athletes (Stolen et al., 2005).

An explanation for the early activation of aerobics can be found in the studies of Stewart et al. (2011), who follow the changes in muscle fiber conduction velocity when performing WAnT. It is known that at supramaximal loads, fast muscle fibers type II is activated first, which is associated with early and significant lactic acid production (Pernov and Wahren, 1968; Carey and Richardson, 2003; Andreeva et al., 2012). The rice of tissue and blood acidity leads to changes in muscle fiber recruitment and to inhibiting energy production, 
hence, limiting work which may contribute to decreasing the acidity and enhancing oxygen supply. Still, the intensity of exercise has to diminish.

\section{CONCLUSIONS}

The study confirmed the hypothesis of the existence of relationships between cardiopulmonary parameters obtained during CPET and WAnT. The correlation between WAnT respiratory parameters and oxygen consumption in CPET is most pronounced. The maximal values of cardiopulmonary parameters achieved in the very different in duration and intensity WAnT and CPET are approximately identical. This gives reason to assume that when conducting WAnT with simultaneous registration of respiration, together with the indices of athlete's power output, it could be obtained reliable information about the magnitude of $\mathrm{VO}_{2} \max$ and other cardiopulmonary parameters of players. This will greatly facilitate the ongoing control of the exercise conditioning status of athletes.

\section{REFERENCES}

Andreeva, L., Stefanova, D., Petrov, L., Zaekov, N., Voiskova, N., Djarova, T., Atanasov, P., Dimitrov, 1. (2012). Blood lactate concentration after aerobic and anaerobic performance testing of female soccer players, Proceeding Book XVI International Scientific Congress "Olympic Sport and Sport for all \& VI International Scientific Congress "Sport, Stress, Adaptation", Sport \& Science Extra

Armstrong, N., Welsman, J. R., Chia, M. (2001). Short-term power output in relation to growth and maturation, $\mathrm{Br} J$ Sports $\mathrm{Med} ; \mathrm{Vol}$ 35, pp.118-124.

Aziz, AR., Chia, M., Teh, KCJ. (2000). The relationship between maximal oxygen uptake and repeated sprint performance indices in field hockey and soccer players, Sports Med
Phys Fitness; 40(3), pp.195-200.

Bangsbo, J. (1994). The physiology of soccer - with special reference to intense intermittent exercise, Acta Physiol Scand, 151: S619.

Carey D, Richardson M. (2003). Can Aerobic and Anaerobic Power be Measured in a 60-Second Maximal Test? J Sports Sci Med.2(4), pp. 151-157. Published online.

Cipryan, L., Gajda, V. (2011). The Influence of Aerobic Power on Repeated Anaerobic, Exercise in Junior Soccer Players, J Hum Kinet.Jun; Vol. 28, pp. 63-71.

Da Silva, JF., Castagna, C., Carminatti, LJ., Foza, V., Guglielmo, LG., \& De Oliveira, FR. (2010). Physiological Demands of Team-Handball Referees during Games, Journal of Strength and Conditioning Research/ National Strength \& Conditioning Association, Vol. 24, pp. 1960-1962.

Di Giminiani, R., Visca, Ch. (2017). Explosive strength and endurance adaptations in young elite soccer players during two soccer seasons, https://doi.org/10.1371

Edwards, AM., Clark, N., Macfadyen, AM. (2003). Lactate and ventilatory thresholds reflect the training status of professional soccer players where maximum aerobic power is unchanged, J Sports Sci Med, Vol. 2, pp. 23-9.

Ferretti G. (2014). Maximal oxygen consumption in healthy humans: theories and facts. Eur J Appl Physiol, 114(10), pp. 2007-36.

Ferreira, RCA., Souza, F., Ribeiro, W., Fernandes, WS., Fagundes, A., Kawaguchi, L., Carolina, S.,Carvalho, C., Lazo-Osorio, R. (2014). Analysis of Power and Aerobic Capacity in Elite Athletes of Both Genres, Practitioners of Different Sports. Advances in Physical Education.4, pp. 202-207.

Gharbi, Z., Dardouri, W., Haj-Sassi,R., Chamari, K., Souissi, N. (2015). Aerobic and anaerobic determinants of repeated sprint ability in team sports athletes, Biol Sport, 32(3), pp. 207-212. 
Hawley, J., Noakes, T. (1992). Peak power output predicts maximal oxygen uptake and performance time in trained cyclists, European Journal of Applied Physiology and Occupational Physiology, Vol. 65, pp. 79-83.

Helgerud, J., Engen, L. C., Wisloff, U., Hoff, J. (2001). Aerobic endurance training improves soccer performance, Medicine and Science in Sports and Exercise, 33(11):1925-1.

Hawley J, Noakes T. (1992). Peak power output predicts maximal oxygen uptake and performance in trained cyclists, Eur J Physiol Vol. 65, pp. 79-83.

Hoff, J. (2005). Training and testing physical capacities for elite soccer players, Journal of Sports Sciences, 23(6), pp. 573 - 582.

Iliev, I. (1974). A method for complex testing of high-class athletes, BSFS, Sofia, 77-86.

Jacobs, I., Tesch A., Bar-Or, Karlsson J., Dotan R. (1983). Lactate in human skeletal muscle after 10 and $30 \mathrm{~s}$ of supramaximal exercise, J. Appl. Physiol Respirat Environ Exercise Physiol, 55(2), pp. 365 - 367.

Koziris, LP., Kraemer, WJ., Patton, JE., Triplett, NT., Fry, AC., Gordon, SE., Knuttgen, HG. (1996). Relationship of aerobic power to anaerobic performance indices, J. Strength and Condo Res, 10(1), pp. 35-39.

Kavanagh, MF., Jacobs, I (1988). Breathby-breath oxygen consumption during performance of the Wingate Test, Can J Sport Sci; 13(1), pp. 91-3.

McMillan, K., Helgerud, J., Macdonald, R., Hoff, J. (2005). Physiological adaptations to soccer specific endurance training in professional youth soccer players, $\mathrm{Br} J$ Sports Med, 39(5), pp. 273-7.

Mc Ardle W., Katch, F., Katch, V. (1996). Exercise Physiology, Williams and Wilkins, Fours Edition, pp. 249.

Medbo, J., Tabata, I. (1989). Relative importance of aerobic and anaerobic energy release during short-lasting exhausting bicycle exercise, J Appl Physiol, 67 (5). pp. 1881-1886.

Nikolaidis, P. (2015). Maximal Heart Rate in Soccer Players: Measured versus Age predicted, Biomed J, 38; 1; 84;131397.

Pernov B, Wahren J. (1968). Lactate and pyruvate formation and oxygen utilization in the women forearm muscles during work of high intensity and varying duration, Acta Physiol Scandin, Vol. 56, pp. 267-285,

Serresse, O., Lortie, G., Bouchard, C., Boulay, MR. (2007). Estimation of the contribution of the various energy systems during maximal work of short duration. PMID: 3253239 DOI:10.1055/s-1025051.

Smith, J, Hill, D. (1991). Contribution of energy systems during a Wingate power test. Br J Sports Med, 25(4): 196-199. DOI: 10.1136/bjsm.25.4.196

Spencer, M., Bishop, D., Dawson, B., Goodman, C. (2005). Physiological and metabolic responses of repeated-sprint activities: specific to field-based team sports, Sports Med.;35(12), pp. 1025-44.

Stefanova, D., Petrova, B. (2017). Wingate Anaerobic Test: Additional physiological interpretation. J Applied Sports Sciences, vol 2, pp. 50-62.

Stewart, D., Farina, D., Shen, Ch., Macaluso, A. (2011). Muscle fiber conduction velocity during a 30-s Wingate anaerobic test, Journal of Electromyography and Kinesiology, Vol. 21, pp. 418-422

Stølen, T., Chamari, K., Castagna, C., Wisløff, U. (2005). Physiology of Soccer, SportsMed.; Vol. 35, pp. 501-536.

Tønnessen, E.,Hem, E.,Leirstein, S., Haugen, T. (2012).VO2 max Characteristics of Male Professional Soccer Players, International Journal of Sports Physiology and Performance, 8(3).

Turner, A., Walker, S., Stembridge, M., Coneyworth, P., Reed, G., Birdsey, L., Reed, G., Barter, P., Moody, J. (2011). A Testing Battery 
for the Assessment of Fitness in Soccer Play- obic power and pubertal peak height velocity ers, Strength and Conditioning Journal www. in Belgian boys, Eur J Appl Physiol Occup nsca-lift.org 23.

Physiol; 57(4), pp. 430-4.

Üçok, K., Gökbel, H., Okudan, N. (2005). Vanderford, ML., Michael, CM., William, The load for the Wingate test: according to SA., Stewart, C., Hamilton, KL. (2004). Physthe bodyweight or lean body mass, Eur J Gen iological and sport-specific skill response of Med; 2(1), pp. 10-13.

Olympic youth soccer athletes. J Strength

Vanden-Eynde, B., Vienne, D., Vuylste- Cond Res; 18(2), pp. 334-42.

ke-Wauters, M., Van Gerven, D. (1988). Aer-

Corresponding author:

Borislava Petrova

Center for Scientific and Applied Research in Sport

National Sports Academy "Vassil Levski"

21, Acad. Stephan Mladenov str.

Sofia, Bulgaria

E-mail: bubetokp79@gmail.com 